\title{
Low Expression of Transforming Growth Factor $\beta$ in the Epithelium of Barrett's Esophagus
}

\author{
Shou-Wu Lee ${ }^{\text {a, b, f, Han-Chung Lien }}{ }^{\text {a, c }}$, Chi-Chen Lin ${ }^{\text {, }}$ \\ Mei-Chin Wen ${ }^{\mathrm{e}}$, Chi-Sen Chang ${ }^{\mathrm{a}, \mathrm{b}}$
}

\begin{abstract}
Background: The aim of this study was to investigate the expression of transforming growth factor $\beta$ (TGF- $\beta$ ) in the different stages of Barrett's esophagus (BE).

Methods: Paired endoscopic esophageal biopsy samples were obtained from patients with BE prospectively. Subjects were classified into three groups: BE, BE with dysplasia, and adenocarcinoma (AC) arising from BE. Biopsy specimens over normal esophageal epithelium and gastric cardiac epithelium of limited cases were done. Four cell lines, HETA1 (human esophageal epithelium), CA-A and CP-C (non-dysplastic metaplasia), and OE33 (AC) were analyzed for quantitative mRNA and Western blotting of TGF- $\beta$.

Results: All 30 subjects with BE were enrolled. Expression of TGF- $\beta$ mRNA in BE were significantly $(P<0.01)$ lower than that in the normal esophagus and cardiac epithelium. The BE tissue showed a lower positive ratio of TGF- $\beta$ immunohistochemical (IHC) stain than the cardiac epithelium. The expression of TGF- $\beta$ mRNA in the cell lines CA-A, CP-3, OE-33, was significantly $(\mathrm{P}<0.05)$ lower than that in the cell line HETA-1. The Western blotting result showed lower TGF- $\beta$ protein expression of the cell lines CA-A, CP-3, and OE-33.
\end{abstract}

Conclusions: The expression of TGF- $\beta$ was lower in the tissue of BE.

Keywords: Barrett's esophagus; Transforming growth factor $\beta$

Manuscript submitted March 22, 2018, accepted April 11, 2018

${ }^{a}$ Division of Gastroenterology, Department of Internal Medicine, Taichung Veterans General Hospital, Taichung, Taiwan

bDepartment of Internal Medicine, Chung Shan Medical University, Taichung, Taiwan

'Department of Internal Medicine, National Yang-Ming University School of Medicine, Taipei, Taiwan

${ }^{\mathrm{d} I n s t i t u t e}$ of Biomedical Sciences, Chung Hsing University, Taichung, Taiwan eDepartment of Pathology, Taichung Veterans General Hospital, Taichung, Taiwan

${ }^{f}$ Corresponding Author: Shou-Wu Lee, Division of Gastroenterology, Department of Internal Medicine, Taichung Veterans General Hospital, Taichung, 1650 Taiwan Boulevard, Sec. 4, Taichung 40705, Taiwan.

Email: ericest@vghtc.gov.tw

doi: https://doi.org/10.14740/gr1009w

\section{Introduction}

Barrett's esophagus (BE) is a premalignant lesion detected in the majority of patients with esophageal adenocarcinoma (AC), and this cancer is associated with a low rate of survival (5-year survival rate, 15 to $20 \%$ ) [1]. Historically, BE is classified as short-segment BE (SSBE), when the distance between the top of the gastric folds and the squamocolumnar junction $(\mathrm{SCJ})$ is less than $3 \mathrm{~cm}$; and long-segment BE (LSBE) is diagnosed when the distance is greater than $3 \mathrm{~cm}$ [1]. The Prague C and $\mathrm{M}$ criteria represent the standard classification system and categorize BE more precisely, based on the circumferential extent (C) and the maximum extent (M) of Barrett's metaplasia [2]. Histologically, BE is defined conceptually as the condition in which the metaplastic columnar epithelium replaces the stratified squamous epithelium that normally lines the distal esophagus $[3,4]$.

The metaplastic columnar epithelium can be further classified into various types depending on specific histological features. The most common are nonintestinal and the specialized intestinal type that is known as columnar metaplasia; the latter is also referred to as intestinal metaplasia (IM). Moreover, Barrett's epithelium appears to progress sequentially from IM to low-grade dysplasia (LGD), high-grade dysplasia (HGD), and finally to invasive $\mathrm{AC}[5]$.

Dysplasia is defined as neoplastic proliferation within epithelial glands that does not affect the basement membrane. Dysplastic changes might be taken as early indicators of incipient malignancy. This is important for a correct diagnosis in patients with BE because they have a 30 - to 40 -fold increased risk for esophageal AC $[6,7]$. However, there are no precise and validated landmarks that delimit the distal extent of the esophagus, and thus there are major confounders when attempting to establish a precise diagnosis of $\mathrm{BE}$ in patients with only short segments of esophageal columnar epithelium.

Transforming growth factor $\beta$ (TGF- $\beta$ ), a pleiotropic cytokine, exerts profound regulatory effects on the differentiation and proliferation of epithelial cells [8]. In many human cancers, there are inactivating mutations in components of the TGF- $\beta$ pathway resulting in uncontrolled proliferation. In addition, TGF- $\beta$ can enhance invasion, motility, and metastasis. TGF- $\beta$ can thus play a dual role in the initiation and malignant progression of human cancer $[9,10]$.

The aim of this study was to explore the expression of TGF- $\beta$ in the different stages of BE. 


\section{Methods}

\section{Study enrolling individuals with BE}

All 30 subjects with BE were enrolled.

\section{Study design and patients}

This study was approved by the review board of Taichung Veterans General Hospital (CF14040), and was conducted according to the ethical guidelines of the Declaration of Helsinki. All patients with BE provided written informed consent, as well as a detailed interview for history and GERD-related symptoms. $\mathrm{BE}$ is defined as the condition in which the metaplastic columnar epithelium replaces the stratified squamous epithelium at the distal esophagus according to AGA guidelines [4].

Paired endoscopic esophageal biopsy samples were obtained from patients with $\mathrm{BE}$ and routine histopathology was conducted prospectively between November 2012 and November 2014. Endoscopic surveillance was performed according to AGA recommendations [4], using white light and narrow band imaging (NBI) high-resolution endoscopy (Olympus, GIF-H260, Tokyo, Japan). Biopsy specimens of any mucosal irregularities and four-quadrant biopsy specimens were obtained at least every $2 \mathrm{~cm}$ at the salmon-colored esophagus. If dysplasia was suspected, then the four-quadrant biopsy specimens were obtained every $1 \mathrm{~cm}$.

Samples of BE tissue, stained with routine hematoxylineosin (HE) stain, were classified by an expert upper gastrointestinal histopathologist into the following groups: 1) BE; 2) $\mathrm{BE}$ with dysplasia; 3) AC arising from BE.

For all of the enrolled cases, biopsy specimens over the normal esophageal epithelium $(2 \mathrm{~cm}$ proximal to $\mathrm{SCJ})$ and gastric cardiac epithelium of these patients were collected for analysis. For each biopsy location, two specimens were taken. One biopsy specimen was snap-frozen in liquid nitrogen and subsequently stored in $0.5 \mathrm{~mL}$ TRIZOL reagent (Life Technologies, Carlsbad, CA) at $-80{ }^{\circ} \mathrm{C}$ until usage for molecular analysis. The other biopsy was used for histopathology and immunohistochemical (IHC) analysis and fixed in 4\% neutralbuffered formalin. The specimens from these two locations were used as the control group for comparison with specimens taken at the esophagus in our enrolled subjects.

\section{Quantitative reverse transcription-polymerase chain reac- tion (RT-PCR) analysis of TGF- $\beta$ gene expression}

Extraction of RNA from formalin-fixed samples and subsequent cDNA synthesis were performed from the tissue of normal esophagus, BE, and cardiac epithelium. PCR reactions were performed in duplicate for each sample, with first strand cDNA synthesis kit (Thermo, RevertAid ${ }^{\mathrm{TM}}$ ). Expression of TGF- $\beta$ was determined with primers and probe supplied by Applied Biosystems. The target gene expression was normalized against mRNA expression of the housekeeping gene glyceraldehyde- 3-phosphate dehydrogenase (GAPDH, Bio Basic Inc.). For each sample under investigation, the amount of target gene mRNA and GAPDH mRNA was determined from a standard curve.

\section{IHC analysis of TGF- $\beta$ expression}

Tissues of BE and cardiac epithelium that had been fixed in neutral buffered formaldehyde and processed into paraffin wax by standard histological methods were compared. Three $\mu \mathrm{m}$-thick sections were cut and placed. Sections were dried overnight at $60{ }^{\circ} \mathrm{C}$. TGF- $\beta$ IHC staining was performed, and these specimens were reviewed until agreement by an expert histopathologist and an expert gastroenterologist was reached. Cytoplasmic staining of TGF- $\beta$ was scored by the percentage of positive cells $(0,<10 \% ; 1,10-25 \% ; 2,26-50 \%$ and $3,>$ $51 \%$ ), where 0 was classified as negative expression and $1-3$ was classified as positive expression [11].

\section{Study using esophageal cell lines}

For this study, cell lines derived from normal epithelium, BE, and its associated AC were used. HETA1 (human esophageal epithelium), CA-A (non-dysplastic metaplasia), CP-C (IM), and OE33 (BE associated AC cell lines) were maintained in DMEM. All cells were supplemented with $10 \%$ fetal bovine serum (FBS), $100 \mathrm{U} /$ $\mathrm{mL}$ penicillin, $100 \mathrm{mg} / \mathrm{mL}$ streptomycin, and $2 \mathrm{mM}$ glutamine.

\section{Quantitative RT-PCR mRNA and Western blotting of TGF- $\beta$ from cell lines}

Extraction of RNA from these cell lines and subsequent cDNA synthesis were performed. PCR reactions were performed in duplicate for each sample. For each sample under investigation, the amount of target gene mRNA and GAPDH mRNA was determined from a standard curve.

Theses cell lines were homogenized in phosphate-buffered saline. Acid-ethanol treatment of the cellular extract was performed. The protein concentration of the acid-ethanol soluble fraction was determined by a bicinchoninic acid protein assay. Proteins in the gels were electrophoretically transferred onto membranes and probed with anti-TGF- $\beta$ antibodies.

\section{Statistical analysis}

All data were entered into a database using SPSS 12.0. Data are expressed as raw, median, mean $\pm \mathrm{SD}$, or $95 \%$ confidence intervals. A P value below 0.05 was considered statistically significant. Statistical comparisons were made using independent $t$-test to compare the TGF- $\beta$ gene expression.

\section{Results}

All 30 patients with BE were enrolled, and the demographic 
Table 1. Characteristic of Individuals (BE Patients $(n=30)$ )

\begin{tabular}{|ll|}
\hline Basic characteristic & $62.00 \pm 16.64$ \\
\hline Age (year) & $23(76.7 \%)$ \\
Gender (male) & $66.78 \pm 11.47$ \\
Body weight $(\mathrm{kg})$ & $24.69 \pm 3.28$ \\
BWI $\left(\mathrm{kg} / \mathrm{m}^{2}\right)$ & $90.27 \pm 9.40$ \\
Waist $(\mathrm{cm})$ & \\
\hline Endoscopic findings & $26(86.7 \%) / 4(13.3 \%)$ \\
\hline SSBE/LSBE & $12(40.0 \%)$ \\
Erosive esophagitis & $6 / 4 / 2 / 0$ \\
$\quad$ L.A. grade A/B/C/D & $12(40.0 \%)$ \\
Hiatal hernia & $2(6.7 \%)$ \\
H. pylori infection & \\
Histological findings & $28(93.4 \%)$ \\
BE & $1(3.3 \%)$ \\
BE with dysplasia & $1(3.3 \%)$ \\
\hline AC &
\end{tabular}

AC: adenocarcinoma; BE: Barrett's esophagus; BMI: body mass index; LSBE: long-sequment Barrett's esophagus; SSBE: short-sequment Barrett's esophagus.

data are displayed in Table 1 . There was male predominance (76.6\%) and the age ranged between 26 and 87 years (median: 62 years). The mean body mass index (BMI) of these individuals was $24.69 \mathrm{~kg} / \mathrm{m}^{2}$, and the mean waist circumference was $90.27 \mathrm{~cm}$. A total of 12 subjects $(40 \%)$ had erosive esophagitis, with most (50\%) classified as Los Angeles grade A. There were 12 individuals $(40.0 \%)$ with hiatal hernia. Helicobacter pylori infection was observed in only two cases $(6.7 \%)$.

There were four (13.3\%) and $26(86.7 \%)$ cases with LSBE and SSBE, respectively. Furthermore, 28 (93.4\%), one $(3.3 \%)$, and one $(3.3 \%)$ cases were classified as BE, BE with dysplasia, and $\mathrm{BE}$-associated $\mathrm{AC}$, respectively.

Some enrolled individuals had GERD-associated symptoms. The most strongly positive symptom was acid regurgitation $(56.7 \%)$, following by lump sensation $(53.3 \%)$, cough
Table 2. TGF- $\beta$ IHC Stain Scores

\begin{tabular}{llllll}
\hline IHC stain & $\mathbf{0}$ & $\mathbf{1 +}$ & $\mathbf{2 +}$ & $\mathbf{3 +}$ & Total \\
\hline GEJ & 10 & 8 & 4 & 1 & 23 \\
Cardiac epithelium & 1 & 0 & 4 & 18 & 23 \\
\hline
\end{tabular}

GEJ: gastroesophageal junction; IHC: immunohistochemical.

(23.3\%), heartburn $(20.0 \%)$, and chest pain (16.7\%). There were six subjects $(20 \%)$ without any of the above GERDassociated symptoms.

The relative values of TGF- $\beta$ mRNA expression in the epithelium of BE, BE with dysplasia, and $\mathrm{AC}$ are shown in Figure 1. Expression of TGF- $\beta$ mRNA in the epithelium of these cases were significantly $(\mathrm{P}$-value $<0.01)$ lower than that in the normal esophagus and gastric cardiac epithelium.

There were 23 cases, comprising 21, one, and one case with $\mathrm{BE}, \mathrm{BE}$ with dysplasia, and $\mathrm{AC}$, respectively, who underwent TGF- $\beta$ IHC staining. The scores of IHC stain between $\mathrm{BE}$ and cardiac epithelium are displayed in Table 2 and Figure 2. The BE tissue (13 of all 23 cases, 56.5\%) exhibited a lower positive ratio of TGF- $\beta$ IHC stain than that of cardiac epithelium (22 of all 23 cases, 95.7\%). In Figure 3, concomitant BE, dysplasia, and $\mathrm{AC}$ were found in one case and negative TGF- $\beta$ IHC stain was found at these different stages of BE.

The relative values of TGF- $\beta$ mRNA expression of the cell lines HETA-1, CA-A, CP-3, OE-33, are shown in Figure 4. The values were significantly $(\mathrm{P}$-value $<0.05)$ lower in the cell lines CA-A, CP-3, OE-33, than those in the cell line HETA-1.

The Western blotting results of TGF- $\beta$ protein expression of the cell lines HETA-1, CA-A, CP-3, OE-33 are displayed in Figure 5. Similarly, decreased expression of TGF- $\beta$ protein value was found in the cell lines CA-A, CP-3, OE-33, while compared to that in the cell line HETA-1.

\section{Discussion}

$\mathrm{BE}$ is becoming an increasingly important disease due to the rapid rise in the incidence of esophageal AC. The development of $\mathrm{BE}$ is thought to involve a multistep sequence from meta-

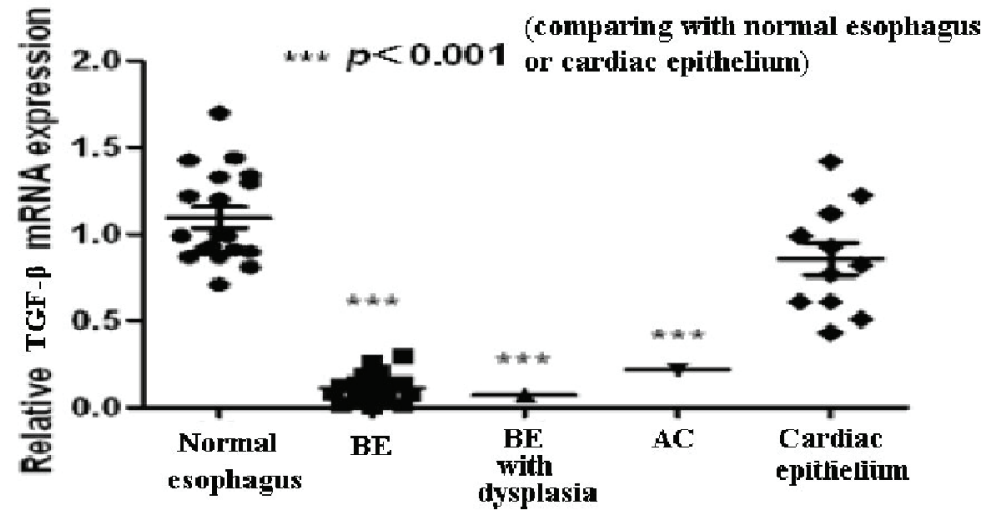

Figure 1. The value of TGF- $\beta$ mRNA in the normal esophagus, Barrett's esophagus (BE), BE with dysplasia, adenocarcinoma (AC), and gastric cardiac epithelium. 


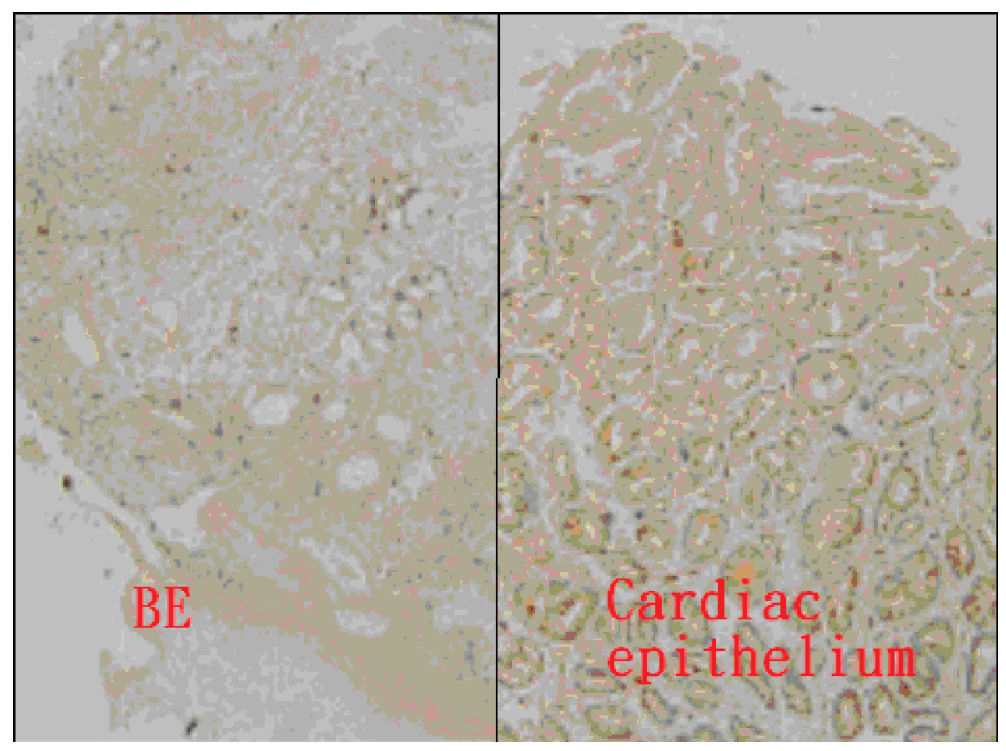

Figure 2. Immunohistochemical analysis of TGF- $\beta$ in Barrett's esophagus (BE) (score 0) and gastric cardiac epithelium (score 3) (magnification $\times 100)$.

plastic columnar epithelium to LGD, progressing to HGD, and, finally, to $\mathrm{AC}[1,12]$. $\mathrm{BE}$ is diagnosed both endoscopically and pathologically. Endoscopic examination can detect a columnar-lined distal esophagus in patients with BE [1].

Histologically, three types of columnar epithelia have been classified in BE: 1) A gastric fundic-type epithelium that has mucus-secreting cells, parietal cells, and chief cells; 2) A cardia-type (junctional-type) epithelium composed almost exclusively of mucus-secreting cells; and 3) An intestinal-type epithelium that contains prominent goblet cells [13]. The fundic- and cardia-type epithelia in $\mathrm{BE}$ can be morphologically indistinguishable from columnar epithelia found in the stomach. Due to the above mentioned reason, if biopsy specimens of suspected BE reveal only fundic- and cardia-type epithelia, it can be difficult to establish that those epithelial types are metaplastic because biopsy sampling error can result in inadvertent biopsy of the stomach instead of the esophagus, especially when only short segments of columnar epithelium appear to extend less than $1 \mathrm{~cm}$ above the gastroesophageal junction (GEJ) [4].

Consequently, endoscopic knowledge of the anatomy of the GEJ is key in the diagnosis of BE. In accordance with current clinical practices, endoscopists generally identify the GEJ as the most proximal extent of the gastric folds, a landmark first proposed in 1987 in a small and methodologically flawed study [14]. However, the location of the proximal extent of

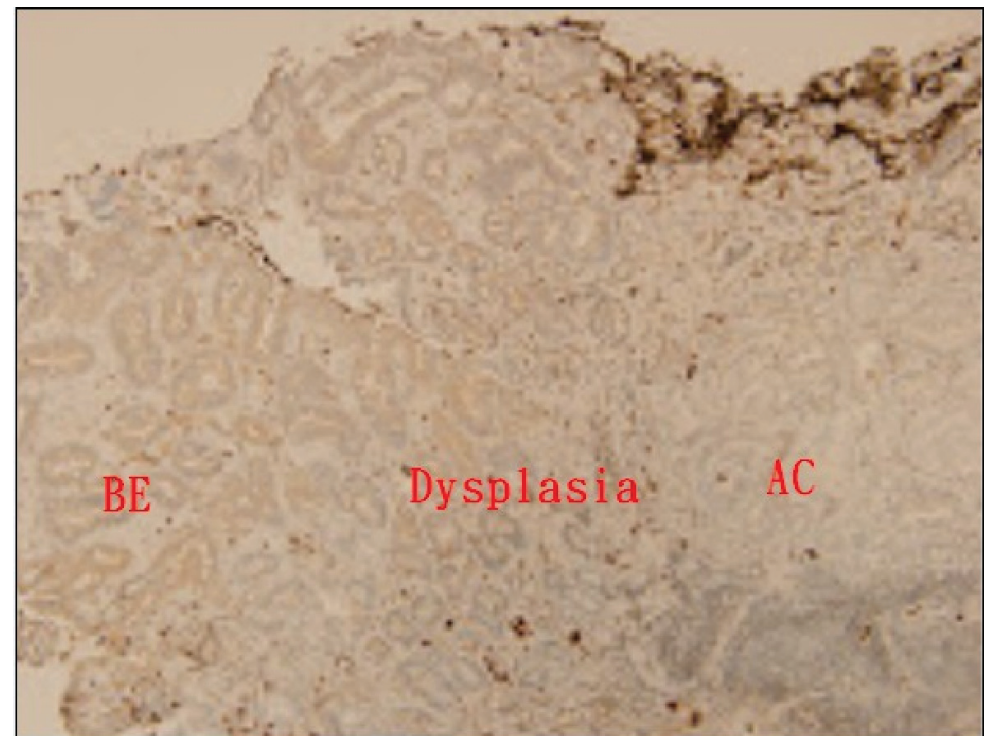

Figure 3. Immunohistochemical analysis of TGF- $\beta$ in Barrett's esophagus (BE), dysplasia, and adenocarcinoma (AC) (all score 0) (magnification $\times 100)$. 


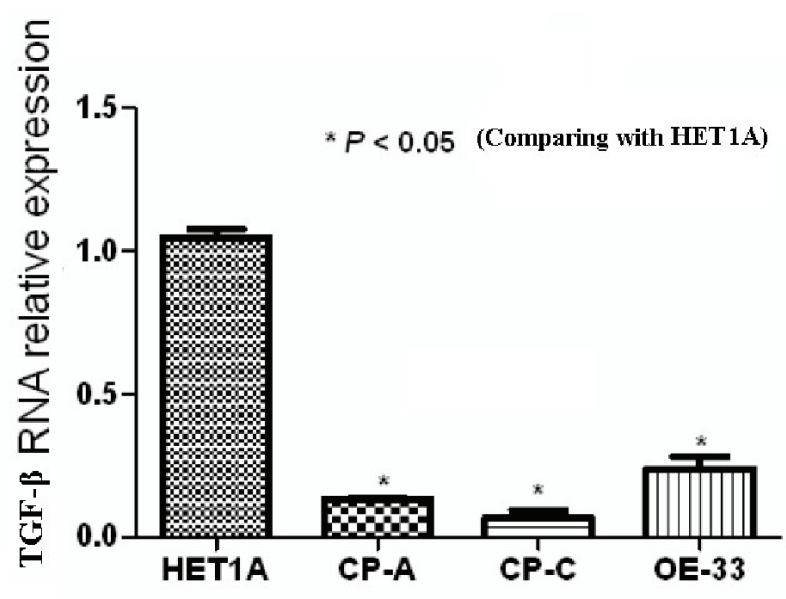

Figure 4. The value of TGF- $\beta$ mRNA of cell lines HETA1, CA-A, CP-C, and OE33.

the gastric folds is easily affected by respiration, gut motor activity, and the degree of distention of the esophagus and stomach, all of which can change from moment to moment [4]. Therefore, identifying a true GEJ specimen obtained from the sampling error-prone cardiac mucosa of patients with $\mathrm{BE}$ is sometimes difficult.

TGF- $\beta$ signaling is initiated by activation of type I and II transmembrane serine/threonine kinase receptors (TbRI and TbRII) which leads to phosphorylation of the intracellular signaling molecules, Smad2 and Smad3. This complex, in association with Smad4, is then translocated into the nucleus resulting in transcriptional regulation of target genes such as downregulation of c-Myc and upregulation of the cyclin-dependent kinase inhibitors p15 and p21 [15]. The net effect of this is to halt the cell cycle in G1, and thus potently inhibit proliferation [16]. Thus, the TGF- $\beta$ signaling pathway restricts carcinogenesis in the earlier stages of various tumors.

Gastrointestinal malignancies frequently display inactivating mutations of the TGF- $\beta$ signaling cascade. In microsatellite unstable tumors, $81 \%$ of colon cancers and $69 \%$ of gastric cancers undergo frameshift mutations of TbRII [17]. Inactivation of Smad4 has been described in $50 \%$ of pancreatic adenocarcinomas, $30 \%$ of metastatic colorectal cancers, and $25 \%$ of small intestinal carcinomas [18-20].

Several previous studies demonstrated that loss of TGF- $\beta$ signaling is an important factor in BE-related AC. Runx 3 , a target gene of TGF- $\beta$ signaling, has also been shown to be down-regulated in BE-associated AC [21, 22]. Smad4 mRNA expression was progressively reduced in the metaplasia-dysplasia-adenocarcinoma sequence and Smad4 promoter methylation was found in $70 \%$ of primary BE-related AC samples [23]. Other evidence suggests that the inability to degrade Skirelated novel protein $\mathrm{N}$ (SnoN) or loss of protein b2-spectrin (b2SP) may be responsible, at least in part, for the unresponsiveness of esophageal cancer to the anti-proliferative effect of TGF- $\beta[24,25]$.

To the best of our knowledge, no studies to date have investigated the expression of TGF- $\beta$ in the epithelium of BE. According to the results of our study, in both biopsy tissue and

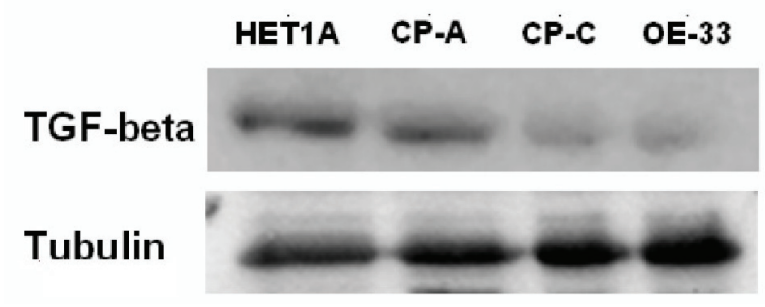

Figure 5. The TGF- $\beta$ Western blotting of cell lines HETA1, CA-A, CP-C, and OE33.

cell lines from the metaplasia-dysplasia-adenocarcinoma sequence, there was a significant reduction in mRNA and protein expression of TGF- $\beta$. Our result suggests that lower expression of TGF- $\beta$ may be a potential biomarker that can be used to confirm the biopsy specimen over the GEJ region, which could be a superior method compared to analysis of specimens from the sampling error-prone cardiac mucosa. This could decrease unnecessary repeated endoscopy surveillance if a "true lesion" biopsy is taken, or may avoid missing dysplasia or malignancy if a "false lesion" biopsy is taken.

There were some limitations in our study. First, our study design was hospital-based and included only a small number of cases. Furthermore, the very small sample size of dysplasia and AC limits the power of this study. Second, only ethnic Chinese cases were enrolled in our study so these findings may not be generalized to other populations. Third, the associated molecules of TGF- $\beta$ signaling, TbR or Smad, were not analyzed in our study. Fourth, in our study, we did not collect GEJ sample of "normal subjects", and it was doubt to conclude low expression of TGF- $\beta$ at the epithelium with intestinalized columnar metaplasia. Last, the expression of TGF- $\beta$ was low in the epithelium of $\mathrm{BE}$ irrespective of the presence of dysplasia or associated AC. The lower expression of TGF- $\beta$ could not explain the carcinogenesis of the metaplasia-dysplasia-adenocarcinoma sequence.

\section{Conclusions}

The expression of TGF- $\beta$ was lower in the tissue of BE. The mechanism remains unclear.

\section{References}

1. Sharma P. Clinical practice. Barrett's esophagus. N Engl J Med. 2009;361(26):2548-2556.

2. Sharma P, Dent J, Armstrong D, Bergman JJ, Gossner L, Hoshihara Y, Jankowski JA, et al. The development and validation of an endoscopic grading system for Barrett's esophagus: the Prague C \& M criteria. Gastroenterology. 2006;131(5):1392-1399.

3. Vakil N, van Zanten SV, Kahrilas P, Dent J, Jones R, Global Consensus G. The Montreal definition and classification of gastroesophageal reflux disease: a global evidencebased consensus. Am J Gastroenterol. 2006;101(8):19001920; quiz 1943. 
4. Sharma P, Katzka DA, Gupta N, Ajani J, Buttar N, Chak A, Corley D, et al. Quality indicators for the management of Barrett's esophagus, dysplasia, and esophageal adenocarcinoma: international consensus recommendations from the American Gastroenterological Association Symposium. Gastroenterology. 2015;149(6):1599-1606.

5. Burke ZD, Tosh D. Barrett's metaplasia as a paradigm for understanding the development of cancer. Curr Opin Genet Dev. 2012;22(5):494-499.

6. O'Shaughnessy JA, Kelloff GJ, Gordon GB, Dannenberg AJ, Hong WK, Fabian CJ, Sigman CC, et al. Treatment and prevention of intraepithelial neoplasia: an important target for accelerated new agent development. Clin Cancer Res. 2002;8(2):314-346.

7. Corley DA, Levin TR, Habel LA, Weiss NS, Buffler PA. Surveillance and survival in Barrett's adenocarcinomas: a population-based study. Gastroenterology. 2002;122(3):633-640.

8. Massague J. TGFbeta in Cancer. Cell. 2008;134(2):215230.

9. Akhurst RJ, Derynck R. TGF-beta signaling in cancer-a double-edged sword. Trends Cell Biol. 2001;11(11):S4451.

10. Onwuegbusi BA, Rees JR, Lao-Sirieix P, Fitzgerald RC. Selective loss of TGFbeta Smad-dependent signalling prevents cell cycle arrest and promotes invasion in oesophageal adenocarcinoma cell lines. PLoS One. 2007;2(1):e177.

11. Xu Z, Wang S, Wu M, Zeng W, Wang X, Dong Z. TGFbetal and HGF protein secretion by esophageal squamous epithelial cells and stromal fibroblasts in oesophageal carcinogenesis. Oncol Lett. 2013;6(2):401-406.

12. Pera M, Cameron AJ, Trastek VF, Carpenter HA, Zinsmeister AR. Increasing incidence of adenocarcinoma of the esophagus and esophagogastric junction. Gastroenterology. 1993;104(2):510-513.

13. Paull A, Trier JS, Dalton MD, Camp RC, Loeb P, Goyal RK. The histologic spectrum of Barrett's esophagus. N Engl J Med. 1976;295(9):476-480.

14. McClave SA, Boyce HW, Jr., Gottfried MR. Early diagnosis of columnar-lined esophagus: a new endoscopic diagnostic criterion. Gastrointest Endosc. 1987;33(6):413416.

15. Massague J. TGF-beta signal transduction. Annu Rev
Biochem. 1998;67:753-791.

16. Zhang Y, Feng XH, Derynck R. Smad3 and Smad4 cooperate with c-Jun/c-Fos to mediate TGF-beta-induced transcription. Nature. 1998;394(6696):909-913.

17. Duval A, Hamelin R. Mutations at coding repeat sequences in mismatch repair-deficient human cancers: toward a new concept of target genes for instability. Cancer Res. 2002;62(9):2447-2454.

18. Hahn SA, Schutte M, Hoque AT, Moskaluk CA, da Costa LT, Rozenblum E, Weinstein CL, et al. DPC4, a candidate tumor suppressor gene at human chromosome 18q21.1. Science. 1996;271(5247):350-353.

19. Miyaki M, Iijima T, Konishi M, Sakai K, Ishii A, Yasuno M, Hishima T, et al. Higher frequency of Smad4 gene mutation in human colorectal cancer with distant metastasis. Oncogene. 1999;18(20):3098-3103.

20. Blaker H, von Herbay A, Penzel R, Gross S, Otto HF. Genetics of adenocarcinomas of the small intestine: frequent deletions at chromosome $18 \mathrm{q}$ and mutations of the SMAD4 gene. Oncogene. 2002;21(1):158-164.

21. Torquati A, O'Rear L, Longobardi L, Spagnoli A, Richards WO, Daniel Beauchamp R. RUNX3 inhibits cell proliferation and induces apoptosis by reinstating transforming growth factor beta responsiveness in esophageal adenocarcinoma cells. Surgery. 2004;136(2):310-316.

22. Schulmann K, Sterian A, Berki A, Yin J, Sato F, Xu Y, Olaru A, et al. Inactivation of p16, RUNX3, and HPP1 occurs early in Barrett's-associated neoplastic progression and predicts progression risk. Oncogene. 2005;24(25):41384148.

23. Onwuegbusi BA, Aitchison A, Chin SF, Kranjac T, Mills I, Huang Y, Lao-Sirieix P, et al. Impaired transforming growth factor beta signalling in Barrett's carcinogenesis due to frequent SMAD4 inactivation. Gut. 2006;55(6):764-774.

24. Edmiston JS, Yeudall WA, Chung TD, Lebman DA. Inability of transforming growth factor-beta to cause SnoN degradation leads to resistance to transforming growth factor-beta-induced growth arrest in esophageal cancer cells. Cancer Res. 2005;65(11):4782-4788.

25. Song S, Maru DM, Ajani JA, Chan CH, Honjo S, Lin HK, Correa A, et al. Loss of TGF-beta adaptor beta2SP activates notch signaling and SOX9 expression in esophageal adenocarcinoma. Cancer Res. 2013;73(7):2159-2169. 